\title{
Lead in petrol and levels of lead in blood: scientific evidence and social policy
}

\author{
P C ELWOOD ${ }^{1}$ AND J E J GALLACHER ${ }^{2}$ \\ From the MRC Epidemiology Unit (South Wales) ${ }^{1}$ and the Welsh National School of Medicine, ${ }^{2}$ Cardiff
}

SUMMARY Two aspects of the recent controversy about the health consequences of lead in petrol are considered. Firstly, the evidence is shown to be deficient, largely because the basic epidemiological principles of representative sampling, realistic measurement, and control of confounding variables were not followed so that valid conclusions cannot be drawn from most of the published studies. Secondly, the role of science appeared to be comprised by confusion between science per se and social policy. Relations between the two are explored, and it is concluded that confusing them reduces the contribution that science can make to effective social policy.

The controversy about lead in petrol has been a curious phenomenon in a number of respects. It appeared to polarise scientific opinion to a degree that is unusual, and it suddenly subsided early in 1983. This last did not appear to be consequent on any new scientific findings or any new insight into available evidence, but it occurred within days of an announcement of a government commitment to reduce lead in petrol. We attempt to examine two aspects of this situation: firstly, the quality of the evidence behind the controversy, and secondly, the relation between science and policy making.

\section{The evidence on lead in petrol}

There are at least three separate views on the evidence on lead in petrol: firstly, that the issue is settled and that there is unequivocal evidence that petrol lead is a major contributor to blood lead; secondly, that the available evidence is capable of such diverse and irreconcilable interpretations that further evidence is unlikely to resolve the debate; and, thirdly, that most of the evidence available at present is of limited relevance, that what there is has been interpreted in a misleading way, and that therefore further evidence is urgently needed. All these three views necessitate an examination of the evidence, and whereas an exhaustive examination is clearly beyond the scope of any single article, the comments that follow relate in particular to studies that were selected by the Environmental Protection Agency for detailed comment, and which seem to have been given special weight by that body in reaching their conclusions. ${ }^{1}$

A basic limitation in most of the published studies is that rarely has an attempt been made to study a representative sample of a defined population, and little or no data are given on the response rate of the subjects invited to cooperate. Without assurance on these aspects of a survey there can be no confident interpretation of the data collected. Gross sampling bias is evident in the reports of some of the surveys quoted in the lead controversy. For example, Angle and McIntyre, ${ }^{2}$ who conducted a survey of children in several areas, stated "virtually all of the urban children are black; all of the suburban children are white." In fact, very few of the studies referred to by the protagonists of a relation between air and blood lead give any assurance on representativeness of study populations; indeed, there is often evidence of marked sample selection during the study. ${ }^{34}$ Furthermore, even if a study were to report data from a sample of subjects with a high response rate, one is still entitled to ask how representative that sample is of the general population. This last is important because conclusions drawn from a study of children living round a lead smelter can hardly be assumed to be relevant to children in general, nor can one reasonably extrapolate from cab drivers in Los Angeles ${ }^{5}$ to the general population.

Another limitation in most studies of the determinants of blood lead is that very little attention is given to the relevance of the measurements made to the actual exposure of human subjects. This is true in studies of most of the environmental sources of lead, but it is particularly true of air lead studies. While the measurement of individual exposures by the use of personal monitors is admirable, and anything less represents a serious compromise, only a very few such studies have been attempted, and these have not been based on subjects representative of any defined population. ${ }^{5}$ On the other hand, the measurements of air lead that are most frequently made are of doubtful relevance to the community, for 
example, measurements made in petrol filling stations, in a motorway tunnel, and in the central reservation of the M4 motorway. ${ }^{6}$ Yet this last is perhaps one of the most frequently quoted sources in the UK literature.

The degree to which outdoor air measurements relate to the exposure of individuals is unknown, but indoor measurements seem to be much more relevant. In one study based on 11 homes, the air lead levels estimated from personal samplers, worn for 12 hours on each of 10 days, correlated well with air lead levels measured indoors, but not so well with levels measured outdoors. ${ }^{7}$ However, we have shown that there is no simple relation between measurements made indoors and outdoors, the ratio indoor:outdoor being much lower for a room at the rear of the dwelling than for a room at the front of the dwelling. ${ }^{8}$ This is highly relevant because subjects who live in dwellings on a main road are likely to make their living room one of the back rooms in order to limit noise and dust.

A further major difficulty in the interpretation of many of the studies that have attempted to evaluate lead in a particular environmental source, in terms of its association with blood lead, is the fact that high levels of lead in one source often occur together with high levels in other sources. For example, in inner cities, air lead levels are high because of the traffic and industry, but, in addition, inner city houses tend in general to be old, and lead levels are likely to be significant in water because of lead piping, and in dust because of old lead paint. This "confounding" of the effects of lead in different sources is likely to be especially serious in many of the studies of the association between lead in blood and lead in air, because air lead is usually estimated at "area" level rather than for each individual subject, and, further, because in many studies no attempt was made to control for the effect of lead in these other sources.

In fact, on reading the reports of population studies one is impressed by the fact that a ratio between blood lead and air lead, which differs significantly from zero, is usually shown only in studies based on samples of two or more communities or occupation groups which differ enormously from each other with respect to social and environmental factors. Granted heterogeneous samples of subjects are usually included in order to achieve a wide range in air lead exposures and hence increase the sensitivity of the study. At the same time, however, the inclusion of heterogeneous groups makes confounding virtually inevitable, and if air lead is measured at area level the confounding of the effects of social, dietary, and unmeasured environmental factors with air lead is inextricable. For example, in three frequently quoted studies, ${ }^{239}$ data from subjects living round a lead smelter have been pooled with data from urban, suburban, and even rural groups, and in these studies even occupational factors are likely to have affected blood lead levels, but their effect will have been attributed to the air effect. ${ }^{10}$

A rather different approach to the evaluation of lead in petrol as a contributor to blood lead was taken in a number of prospective studies which examined the effect on blood lead of a change in petrol lead. In the Isotopic Lead Experiment ${ }^{11}$ lead with an unusual ratio of two isotopes was added to all the petrol sold in Piedmont for two years. The change in the isotopic ratio of lead in the blood of residents was monitored, and estimates were made of the contribution of petrol lead to blood. While technical aspects seem to have been excellent, the design of the study was deplorable. ${ }^{12}$ No control area was included, and conclusions were based on a very small unrepresentative sample of subjects. In the NHANES II study, a fall in the mean blood lead levels of sequential samples of subjects seen during the period when lead in petrol was reduced in the USA was used to derive a quantitative estimate of the contribution of petrol lead to blood. ${ }^{13}$ There are many uncertainties in this work, and strictly the NHANES II lead data are uninterpretable because of the absence of "control" data. ${ }^{14}$ In the UK, the results of two nationwide surveys suggest a fall in blood lead level despite little change in petrol lead, ${ }^{15}{ }^{16}$ and supportive evidence comes from studies in Wales. ${ }^{17} 18$

It seems therefore that any claim that theso contribution of petrol lead to blood lead is known for? a representative sample of the population of any country is untenable. The argument that the issue has been resolved beyond "reasonable" doubt still remains a matter of judgement, but it seems that abuses of the epidemiological approach have been so serious in most of the published studies that it is unlikely that any critical scientist would find the evidence convincing. The position that further evidence is unlikely to settle the issue, as has been argued in detail by Collingridge and Douglas, ${ }^{19}$ turns on the intense attention and criticism given to all studies of the health effects of lead in petrol. They conclude that scrutiny of work on lead is so close that there will be increasing difficulties of interpretation, whatever the evidence. This is a dangerous argument, as it applies in principle to all science, removing the possibility of progress if there is sufficient scrutiny. The argument is, however, false as a distinction should be made between the settling of old issues and the raising of new ones. Once a problem has been identified, such as assaying the relevance to blood lead of air lead measured in various ways, it can be resolved. Of course, further evidence on any 
hypothesis will produce new issues, but progress will have been made. A clearer statement of Collingridge's dilemma might be that the closer the scrutiny the slower, but the more secure, the progress. Finally, there is the view that more research of greater relevance is needed. In fact, this point of view reflects an attitude that is implicit in any critical literature review but is certainly a fair conclusion to draw in this case. Clearly more pertinent studies are required. The issue of lead will be difficult to resolve, and although resolvable it will not be done quickly or easily.

\section{The relation between science and social policy}

It is worrying that social policy on lead in the UK has been formulated on the basis of very poor scientific evidence, and scientists bear a heavy responsibility for the paucity of good, relevant evidence. However, even more worrying is the fact that, although the controversy about lead was conducted under the aegis of science, largely non-scientific considerations seem to have been paramount. Serious questions are therefore raised on the role of science and scientist in society, particularly as to how science should relate to social policy.

Several views have been expressed on the relation between science and the formulation of social policy in the control of environmental lead. Rutter discusses the relation between science and value judgements but concludes the two to be inextricably linked before he goes on to draw his conclusions on policy. ${ }^{20}$ Collingridge $e$ al $^{1921}$ conclude that, as far as lead is concerned, science probably had more of an ad hoc than a systematic influence, but they do not suggest how important science ought to be. Johnston ${ }^{22}$ provides a synopsis of the various groups within society that influence social policy, and he suggests that insularity between scientific disciplines leads to contradictory scientific advice, but again no analysis of the proper relation between science and social policy is made. Unfortunately, none of these views clarifies our understanding of the principles involved in relating science to social policy. If this is to be achieved, it must begin with an understanding of society.

For the purposes of this article a largely Popperian $^{23}$ view of society is adopted. Society is considered to be, among other things, a problem solving institution in which improvement is facilitated by the freedom to evaluate critically the effects of society's activities, particularly its formal policies. For present purposes, the role of social policy in society is to effect change in the search for improvement, and the role of science in society is to provide the firmest possible empirical grounds for change, that is, to minimise prediction error in the formation of policy. This view of society, social policy, and science is particularly helpful when considering lead, as it does not presume any particular values or interests, whether they be political, financial, or ecological. It is applicable whatever values or interests are held. Within this view science serves to facilitate the optimal allocation of society's resources according to society's values by providing an empirical basis for policy.

It is clear from this view of society that science and social policy have asymmetric relations. Social policy determines which hypotheses are sufficiently important to be tested but cannot legitimately influence the interpretation of the data in terms of predictive relations. Science, on the other hand, can serve only to predict and cannot legitimately interpret the social importance of the predictions. This asymmetry is made more obvious if the processes involved in arriving at scientific conclusions and at social policy are briefly considered. Scientific conclusions are arrived at after subjecting the available data to the most severe scrútiny and impartial criticism in order to determine those interpretations of the data that may be made on purely. rational grounds. Social policy is made as a result of compromise between conflicting interests in society and essentially involves consensus rather than rational argument. Therefore although the results of the two processes may well affect each other, and although one always hopes that the best argument will be the most influential in both, the two processes are quite distinct and must be conducted exclusively on their own terms. If these distinctions are not observed, both science and social policy will suffer: the contribution of science will become less trustworthy and the outcome of policy less secure. It appears that in the case of lead it may have been the blurring of these distinctions that reduced the scientific defensibility of policy.

Much of the blame for the failure to distinguish between science and social policy in the controversy about lead seems to lie with scientists who have confused their role as scientists with their role as members of the public. During the course of the controversy many scientific articles were concluded with an irrelevant call for a change in social policy. A scientist has the responsibility to decide what conclusions may or may not be drawn from available data. A member of the public has the right to hold any manner of private belief, whatever the evidence. For scientists to express a view which goes beyond the available data and not to make it clear that the view is either speculative or is a matter of personal belief, is irresponsible, particularly when he is writing in the scientific press. Of further importance is the fact that 
partisanship based on personal beliefs is likely to lead a scientist to bias in the interpretation of data and in the making of predictions. This is likely to divert attention and resources away from the steady and relatively secure progress of knowledge to the promotion of personal beliefs. Although no scientist is perfect, and impartiality is always difficult to achieve, scientists themselves should be the first to perceive the importance of impartial criticism as a major factor in scientific progress and the importance of separating this factor from personal sympathies and beliefs.

Further blame for blurring the distinctions between science and social policy on lead in petrol may be attributed to interested parties whose primary aim is to change public opinion. The role of such groups in society is to bring to notice issues of possible public concern, and to attempt to promote changes which they believe would lead to an improvement in social conditions. However, such groups often act as though incontrovertible facts can be adduced in their favour. In this way they impersonate the scientist, but a scientist who by some mysterious ability has been able to reject the null hypothesis without conducting the study. Indeed, the vigour with which such groups pursue their objective, and the vehemence with which they rebut any evidence or opinion contrary to their objective, can inhibit further scientific enquiry. The danger of such groups going beyond their proper area of usefulness to society is made more acute by their increasing professionalisation. To the extent that this increases the effectiveness of communication and so further increases public awareness it is acceptable, and to the extent that it puts them on a more equal footing with their protagonists it can be sympathised with. But insofar as it turns such groups into business concerns employing professional campaigners, it is worrying. The credibility of any group or interested party wishing to change public opinion on an issue of public interest must depend on the validity of their case, which ultimately can be demonstrated only by reasoned argument. A business, however, operates to market successfully its products by whatever legitimate means are available. When an issue of public concern is treated as a commodity, the sense of proportion by which the issue might be judged is lost. A reverse logic applies, the issue becomes as important as its advertising campaign is successful.

\section{References}

- 1 US Environmental Protection Agency. Air quality criteria for lead. Quoted in EPA-600/8-83-028A. August 1983.

${ }^{2}$ Angle CR, McIntire MS. Environmental lead and children. The Omaha study.J Toxic Environ Hlth 1979; 5: 855-70.
${ }^{3}$ Roels HA, Buchet J-P, Lauwerys RR, Bruaux P, Claeys-Thoreau F, Lafontaine A, Verduyn G. Exposure to lead by the oral and the pulmonary routes of children living in the vicinity of a primary lead smelter. Environmental Research 1980; 22: 81-94.

${ }^{4}$ Waldron HA. Lead levels in blood of residents near the M6-A38(M) interchange, Birmingham. Nature 1975; 253: $345-6$.

${ }^{5}$ Azar A, Snee RD, Habibi K. An epidemiologic approach to community air lead exposure using personal air samplers. In: Lead. Environ Qual Saf 1975; Suppl. 2: 254-88.

${ }^{6}$ Transport and Road Research Laboratory. The concentration of volatile and particulate lead compounds in the atmosphere: the measurement at four road sites. Report LR 545. Transport and Road Research Laboratory: Department of the Environment 1973.

${ }^{7}$ Tosteson TD, Spengler JD, Weker RA. Aluminium, iron and lead content of respirable particulate samples from a personal monitoring study. Environment International 1982; 8: 265-8.

${ }^{8}$ Elwood PC. The lead debate. Env Hlth 1984; 92 (1): 12-4.

${ }^{9}$ Yankel AJ, Von Lindern IH, Walter SD. The Silver Valley lead study: the relationship between childhood blood lead levels and environmental exposure. J Air Pollution Control Association 1977; 27: 763-7.

${ }^{10}$ Elwood WJ, Clayton BE, Cox RA, Delves HT, King E, Malcolm D, Ratcliffe JM, Taylor JF. Lead in human blood and in the environment near a battery factory. Brit J Prev Soc Med 1978; 31: 154-63.

${ }^{11}$ Facchetti S, Geiss F, Caglione P, Colombo A, Garibaldi G, Spallanzani G, Gilli G. Isotopic lead experiment: Status report. Brussels: Commission of the European Communities, 1982.

${ }^{12}$ Elwood PC. Turin isotopic lead experiment. Lancet 1983; i: 869.

${ }^{13}$ Annest JL, Pirkle JL, Makuc D, Neese JW, Bayse DD, Kovar MG. Chronological trend in blood lead levels between 1976 and 1980. New Engl J Med 1983; 308: 1373-7.

${ }^{14}$ Elwood PC, Gallacher J. Blood lead levels 1976-80. New Engl J Med 1983; 310: 1125.

${ }^{15}$ Department of the Environment. European Community screening programme for lead: United Kingdom results for 1979-1980. Pollution Report No. 10. London: DoE, 1981.

${ }^{16}$ Department of the Environment. European Community screening programme for lead: United Kingdom results for 1981. Pollution Report No. 18. London: DoE, 1983.

${ }^{17}$ Elwood PC. Blood lead and petrol lead. Br Med J 1983; 286: 1515.

${ }^{18}$ Elwood PC. Changes in blood lead concentrations in women in Wales 1972-82. Br Med J 1983; 286: 1553-5.

${ }^{19}$ Collingridge $\mathrm{D}$, Douglas J. Three models of policy making-expert advice in the control of lead. Social Studies of Science 1984; in press.

${ }^{20}$ Rutter M. The relationship between science and social policy making: the case of lead. Clean Air 1983; 13: $1-16$.

${ }^{21}$ Collingridge D, McEvoy J. A cost effective comparison of controls on environmental lead: a decision methodology. International Journal of Environmental Science 1981; 16: 139-45.

22 Johnston AP. Policy makers, scientific evidence and pressure groups. In: Plwm yng Nghymru: Lead in Wales. Cardiff: MRC Epidemiology Unit, ISBN 0950895105, 1983.

${ }^{23}$ Popper KR. The open society and its enemies. London: Routledge \& Kegan Paul, 1945. 